\title{
Analyzing the Impact of Nurses Emotional Intelligence on Pa- tients Quality-of-Care with the Mediating Role of Job Involve- ment
}

\author{
Dr. Irfan Sabir*1, Azhar Tanveer², Muhammad Bilal Majid ${ }^{3} \&$ Prof. Dr. Mohd \\ Sadad Mahmud ${ }^{4}$ \\ ${ }^{1}$ University of Central Punjab (UCP) Sialkot Campus, Pakistan \\ ${ }^{2}$ COMSATS University Islamabad, Pakistan \\ 3,4 Universiti Sultan Zainal Abidin (UniSZA) Gong Badak Campus, Malaysia
}

\begin{abstract}
The aim of the current study was to analyze the impact of Nurses Emotional Intelligence on Patients Quality-of-Care with the mediating role of Job Involvement. Deductive approach was used to study the constructs, derived from theory. Research hypotheses are formulated from existing theory and knowledge relating to emotional intelligence and patientscentered care. The sample was calculated through an online calculator "Raosoft". The recommended final simple size was 292 with a population size of 1200 at $95 \%$ confidence level, $5 \%$ error of margin and 50\% response distribution. Correlations and regression analysis were performed to measure the mediation analysis. The statistical outcomes confirmed nurses emotional intelligence positively affects patients quality of care. Furthermore, the association between emotional intelligence and job involvement and job involvement and patients quality of care are also positive. Job involvement has a partial mediation impact in the said association. The study concludes by discussing future research directions.
\end{abstract}

\section{Introduction}

In today's economic age, many businesses gain too much success and others do not. The business success or failure is personal ability of employees and executives. The most significant factor is emotions. Emotions play an important role in human success and affect all aspects of life. Every emotion has different kind of characteristics that can reflect in their work (Ahangar, 2012). The phenomenon of Emotional intelligence (EI) in the field of nursing is new to some extent. This concept was covered in 2002 in an English peer-reviewed journal (Kooker et al., 2007). After that researcher's started to develop interest in emotional intelligence (EI) as a mean to develop the various aspects of nursing including leadership, education and practice. The term emotional intelligence is used interchangeably as Emotional Quotient (EQ). Emotional Intelligence is a critical aspect that can predict human psychological well-being and life stability (Obaidi et al., 2018).

*Corresponding author.

Email: irfansabir@gmail.com

http:/ /www.jbrc.pk

(C) Jinnah Business Review 
The main determinant of patient's care quality is patient-centered care (PCC). According to Institute of Medicine, patient-centered care has six important aspects; safety, effectiveness, time, efficient, quality and equitable care. The quality of patient's care is revolving around the behavior and emotions of nurses. Dandona et al. (2002) stated that better awareness of healthcare among public increases the demand for quality of care and more health regulations of malpractices in public healthcare. The quality of healthcare practices is not possible without the help of nurses

It is evident that only technical competence and high intelligence are not sufficient for patient's quality of care. The role of emotional intelligence is very important in patient's care. Celik (2017) analyzed the association between emotional intelligence and patient's satisfaction. This study proposes that emotional intelligence is the significant quality indicator to improve the quality of healthcare services. In another study, Ezzatabadi et al. (2012) determined the role of nurse's emotional intelligence on hospital services quality. The outcome indicated that emotional intelligence has direct impact on service quality. Berghout et al. (2015) affirmed that emotional support dimension has been provided a transitional importance for patient-centered care.

Job involvement means the degree to which an employee gives importance to their job during their life, i.e. central life interest (Griffin et al., 2012). The concept of job involvement is explained through a well-known phrase "I live, eat and breathe my job" (DeCarufel and Schaan, 1990). As per literature, (Lin, 2013) stated the constructs that directly affect job involvement include training and professional competency. The presence of job negativism rises with experience and age of the respondents. In a number of studies, job involvement act as a mediator variable; Kalhor et al. (2018) studied the effect of work values on nurse's organizational commitment with mediating role of job involvement. The nurses with high job involvement were more committed to their organization than nurse having low job involvement. Biswas (2009) stated job involvement as attitudinal variables and their mediator impact on the association of psychological climate and turnover intention. The statistical analysis illustrated that job involvement acts as a quasi-mediator in the above stated relationship.

\subsection{Problem Statement}

The significance of emotional intelligence in healthcare setting seems obvious; when healthcare professional has a high level of emotional intelligence, they are more compassionate, strong and empathic, consequently showing more care for themselves and their patients. Indeed, different research studies indicated that nurses respond emotionally to their patient's (Nightingale et al., 2018; Raghubir, 2018). Healthcare sector is ever changing; at global level the nursing turnover is high as compared to other healthcare professions. The shortage of nurses not only has an impact on patient's quality of life but also has long term effect on economic and social ramifications (Ferrara et al., 2010). Nurse's emotional intelligence has been linked with patient's satisfaction and has been recognized as the quality indicator to enhance the quality of healthcare services (Gülay Ogelman et al., 2017). The nurse's communication skills and job satisfaction have a middle role in emotional intelligence and service quality (Ezzatabadi et al., 2012).

Nowadays, emotional intelligence has gained importance in nursing profession due to their high turnover rate that directly affects the quality of patient care. In previous research studies the association between nurse's emotional intelligence and patient's care were discussed mostly in developed countries. Most of the research papers discussed emotional intelligence in healthcare setting in boarder spectrum, like (Khan et al., 2017) analyzed the emotional intelligence role in 
healthcare administration. Empirical studies that link nurse's emotional intelligence and patient -centered care are scarce in Pakistan healthcare sector. Another factor that gained importance is job involvement that significantly enhances the behavioral association. In spite of theoretical support, very limited literature was found on job involvement among healthcare personnel.

\section{Literature Review}

\subsection{Emotional Intelligence in Nursing Profession}

Nurses have a close and regular association with patients and their attendants and therefore they are exceptionally sensitive to needs, preferences and emotions of the patient's. Ferrara et al. (2010) affirmed that emotional intelligence in nursing profession affect their wellbeing and performance and is considered as one of the most influential factors in personal and organizational performance. In the review study of Birks and Watt (2007), they affirmed that nurses emotional intelligence efficiently improve the healthcare outcomes and patient-centered care. Furthermore, Miao et al. (2016) investigated the moderating role of emotional intelligence in the relationship of nurses' occupational burnout and patient-rated quality of care. The statistical results indicated that emotional intelligence as a moderator among nurses was not significantly correlated with occupational burnout and quality of care. The moderator role of emotional intelligence has also been investigated by Yao et al. (2018) among nurses. The results depicted that the effect of emotional intelligence among job demands, job resources and burnout were partially moderated. Shahnavazi et al. (2018) examined the effect of nurse's emotional intelligence on patient's quality of care during nursing education. The results indicated that in nursing education, emotional intelligence must be studied as a subject and incorporated as pre-qualifying nursing degree as well as professional development programs. Moreover, experienced nurses need to lead young nurses for applying emotional intelligence in routine patient's care practices.

Nightingale et al. (2018) studied the additional factors of emotional intelligence that affect the caring behavior of nurses and other healthcare staff. The results depicted that there were three main participants of emotional intelligence; physicians, nurses head and nurses. The emotional intelligence notation is less relevant to physicians and nurses head but more relevant to nurse's physical and emotional caring. Furthermore, age, experience, job satisfaction and burnout are the relevant factors of emotional intelligence and caring behavior. Another study by Raghubir (2018) clarified the attributes related to emotional intelligence in advance nursing practices. The common attribute of emotional intelligence are self-awareness, self-management, social awareness and social management in advance nursing practices. Emotional intelligence has an impact on job satisfaction, burnout, facilitates positive environment and helps manage stress level. Moreover, emotional intelligence has an explicit effect on patient's quality of care, critical thinking, decision making and overall well-being in advance nursing practice (Raghubir, 2018).

The extensive research work confirmed that nurses with high emotional intelligence may demonstrated more significant role and socially more engaged in patient's quality of care. Hence, nurses with high level of emotional intelligence had low level of stress and high level of perceived competency. 


\subsection{Patient Quality of Care}

In the service sector, the meaning of quality is different from good markets and generally considered an abstract term. The measurement of service quality has become more difficult than quality of goods. In healthcare sector the quality term is measured through patient-centered care (PCC) (Berghout et al., 2015). The outcome of PCC improves patient survival, well-being and greater patient satisfaction. The role of healthcare professional is vital in delivering the patient's quality of care. Ezzatabadi et al. (2012) examined the role of nurse's emotional intelligence on the hospital quality of services. The consequences confirmed that emotional intelligence of nurses has a direct impact on hospital service quality. The outcome also confirmed that nurse's communication skills and job satisfaction act an intermediate between emotional intelligence and service quality association. Celik (2017) inspected the association between nurse's emotional intelligence and patient's satisfaction. The outcome confirmed that the association was significantly positive and recognized as the quality indicator to enhance quality of healthcare services.

Patient-centered care has generally been recognized as primary approach to measure the healthcare quality indicators. This approach highlights the relationship among healthcare personnel's, patients and their family. It provides benefits to healthcare professionals and patient's (Delaney, 2018). Kreindler et al. (2012) in their study examined the politics of patient-centered care. The systematic results indicated that PCC can be served as a weapon on an intergroup battlefield. Ismail et al. (2017) conducted a patient-pathway analysis to analyze the patient'scentered care at the basic healthcare levels in Pakistan. The results described that only few patients were satisfied with quality of services at primary healthcare levels. Hudson et al. (2004) emphasized that role of nurse in patient-centered care is that of a navigator. Outcome of this thematic analysis depicted that nurses were the central contact person among patients, physicians and attendants. Nurses as a navigator help patients in their own health-related decision making and advisory services.

A consumer-driven healthcare approach in patient-centered care for older patients was applied in Jayadevappa (2017) research work. The results acknowledge that patients-centered care effectively integrates value-based care that improves the community well-being and overall quality of care. Bertakis et al. (2000) analyzed that patients-centered care is associated with financial aspects of healthcare through an interactional analysis approach. The outcomes illustrated that patients-centered care efficiently lowers the annual medical care charges and decrease utilization of healthcare services. Mwachofi et al. (2011) analyzed the organizational and socioeconomic factors that affect patient's quality and safety. The findings depicted that factors like communication, fewer visible errors, support of information technology and confidential error reporting system improve the patient's quality of care and safety. The most influential work on patients-centered care was conducted by Picker institute in (1987) and established eight principles for patient-centered care; preferences, emotional support physical comfort, information \& education, continuity \& transition, coordination of care, access to care and family and friends.

\subsection{Job Involvement as Mediator}

The contribution of job involvement in work has gained considerable attention to many psychologists and researchers. In this research study, job involvement signifies the nurse's attitude toward their work and generally defines that the degree to which an individual identified psychologically at their workplace. Job involvement relates to current job and current employment. The mediating role of job involvement was identified by Ćulibrk et al. (2018) in transition 
economies. This empirical research work identified the association between work characteristics, job satisfaction, job involvement and organizational obligation. The results indicated that job involvement partially mediates the association among variables. Kreindler et al. (2012) investigated the impact of work values on organizational commitment with mediating role of job involvement in nursing profession. The results indicated that job involvement has positive association with work values and organizational commitment. Furthermore, job involvement was an important element in mediation analysis. The individual with high job involvement had shown more commitment at their workplace. Another study by Biswas (2009) examined the association between psychological climate and turnover intention among managers/executives with two attitudinal variables job satisfaction and job involvement acting as mediator. The statistical outcome confirmed that job involvement can act as a mediator between manager's psychological climate and turnover. Job involvement has positive association with psychological climate and negative association with turnover intention.

Metcalfe (2017) examined the sale person perception toward their immediate leader's emotional intelligence that impacts their creativity with two attitudinal variables as mediator; job involvement and self-efficacy. The results depicted that job involvement has positive association with emotional intelligence and creativity. Moreover, job involvement mediates the association between emotional intelligence and creativity relationship. Mahmoud (2017) examined the mediating role of job involvement between job crafting and head nurses organizational citizenship behavior. The results depicted that job involvement has positive and significant association with job crafting and organizational citizenship behavior. Furthermore, job involvement has mediated the stated association.

In the dimensional analysis of Singh and Sarkar (2012) examined the association between psychological empowerment and innovative behavior with job involvement as mediator. The statistical results indicated that job involvement has partially mediated the innovative behavior and meaning as psychological empowerment dimension. Whereas, job involvement mediated the innovative behavior and non-work domain control (psychological empowerment dimension). No mediation was found between competence, impact, self-determination at job \& organization level and innovative behavior. Ting (2014) examined the association between school internal marketing and organizational commitment of teachers with mediating role of job involvement and job satisfaction. The job involvement constructs sub-divided into quality upgrading, sacrifice of time and full devotion. The results indicated that job involvement partially mediates the association of internal marketing and teacher's commitment towards their organizations. Kappagoda et al. (2014) investigated the mediating role of job involvement between the relationship of organizational commitment and job performance. The results indicated that job involvement partially mediate the stated relationship.

\subsection{Research Model}

\subsubsection{Research Hypotheses}

$H_{1}$ : The association between emotional intelligence and patient quality-of-care is positive and significant.

$H_{2}$ : The association between emotional intelligence and job involvement is positive and significant.

$H_{3}$ : The association between job involvement and patient quality-of-care is positive and significant. 
$\mathrm{H}_{4}$ : Job involvement plays a mediating role between the association of emotional intelligence and patient's quality-of-care.

\section{Research Methodology}

\subsection{Research Design}

Deductive approach was used to study the constructs derived from theory. Research hypotheses are formulated from existing theory and knowledge relating to emotional intelligence and patient-centered care. Hence, the survey research strategy is used to study the association among constructs. Data are gathered through questionnaire in numeric form to understand the respondent's perspective. So, quantitative research choice is applied.

\subsection{Population and Sample Size}

In the current research target population is the nurses and patients, whereas nurses performing their job in Pakistan government hospitals, specifically in Punjab province are the accessible population.

The sample is calculated through an online website "Raosoft". The recommended final simple size is 292 with a population size of 1200 at $95 \%$ confidence level, $5 \%$ error of margin and $50 \%$ response distribution.

\subsection{Sampling Technique}

In the current research work, probability or representative sampling technique was used. This sampling technique divided into simple-random, systematic, stratified random, cluster and multi stage sampling.

\subsection{Measurement Scale and Instruments}

\subsubsection{Emotional Intelligence (EI)}

The measurement scale of emotional intelligence was adapted by the research of Cooper and Petrides (2010). There are six items in emotional intelligence; all concerned items are measured through five point likert scale from 01 to 05 . Where 01 indicates strongly disagree, 03 represents neutral and 05 indicates strongly agree.

\subsubsection{Job Involvement (JI)}

The measurement scale of job involvement was adapted by Jans (1985) and Paterson and O'Driscoll (1990). There are six items in job involvement all items are measured through five point Likert scale from 01 to 05 . Where 01 indicates strongly disagree, 03 represents neutral and 05 indicates strongly agree. 


\subsubsection{Patient Quality of Care}

The measurement scale of quality of care was adapted of Salomon et al. (1999). There are seven items in patient's quality of care all items are measured through five point likert scale from 01 to 05 . Where 01 indicates strongly disagree, 03 represents neutral and 05 indicates strongly agree.

\section{Data Analysis and Result}

Table 4.1: Reliability or Internal Consistency

\begin{tabular}{|c|c|c|c|c|c|}
\hline \multicolumn{2}{|c|}{ Emotional Intelligence (EI) } & \multicolumn{2}{c|}{ Job Involvement (JI) } & \multicolumn{2}{c|}{ Quality-of-Care (QoC) } \\
\hline \multicolumn{2}{|c|}{ Reliability Statistics } & \multicolumn{2}{|c|}{ Reliability Statistics } & \multicolumn{2}{c|}{ Reliability Statistics } \\
\hline Cronbach's Alpha & N of Items & Cronbach's Alpha & N of Items & Cronbach's Alpha & N of Items \\
\hline 0.796 & 6 & 0.803 & 6 & 0.866 & 7 \\
\hline
\end{tabular}

The most frequent method to calculate the reliability or internal consistency of the constructs is Cronbach's Alpha. This technique required that scale items must be at a regular interval (Sreejesh et al., 2014). The value of alpha varies between 1 (perfect) and 0 (no reliability). As the rule of thumb, the Cronbach's Alpha value 0.80 is considered as the acceptable level of internal reliability but many researchers emphasized that 0.60 is the minimum value of internal reliability (Bryman and Becker, 2012).

In the above table, the alpha value of EI is 0.796 of 06 items, JI has alpha value 0.803 of 6 items and QoC alpha value is 0.866 of 7 items. These values indicated that all constructs have high internal consistency.

\subsection{Correlation}

Table 4.2: Correlation

\begin{tabular}{clccc}
\hline & & EI & JI & QoC \\
\hline \multirow{2}{*}{ EI } & Pearson Correlation & 1 & $.661^{* *}$ & $.637^{* *}$ \\
& Sig. (2-tailed) & & 0 & 0 \\
\multirow{2}{*}{ JI } & Pearson Correlation & $.661^{* *}$ & 1 & $.703^{* *}$ \\
& Sig. (2-tailed) & 0 & & 0 \\
\multirow{2}{*}{ QoC } & Pearson Correlation & $.637^{* *}$ & $.703^{* *}$ & 1 \\
& Sig. (2-tailed) & 0 & 0 & \\
\hline
\end{tabular}

**. Correlation is significant at the 0.01 level (2-tailed).

b. Listwise $N=235$ 
Correlation measurement is a precise estimate to measure the degree of relationship among all study constructs. Generally, correlation is measured through Pearson correlation (r) between interval variables. The value close to zero or zero means weak or no correlation; whereas value close to 1 means strong correlation. The direction of correlation is either positive or negative (Bryman and Becker, 2012).

In the above table the association between $\mathrm{EI}$ and QoC is $63 \%$ that means strong correlation in positive direction and the association between JI and QoC is 70\% is also strong and positive (Wang et al., 1999).

\subsection{Mediation Analysis using SPSS Process Tool}

Preacher and Hayes (2008) presented the concept of conditional indirect effect of moderation mediation in five different models through formulas, SE and bootstrap approach. In this research study, research analysis the mediation process through "process" SPSS tools introduced by Hayes.

\subsubsection{Assumption}

To run the Hayes and Preacher (2010) process tools for mediation, there are two assumption; the association between $\mathrm{X}$ and $\mathrm{Y}$ are liner to minimize the error and normality of estimation error. The linearity and homoscedasticity assumption were checked through multiple regression residual values and standardized predicted.

As seen in the above scree plot, the regression appears linear since the loess curve centers close to zero along the entire x-axis. The researcher observes the above scree plot to examine the homoscedasticity, on Y-axis the data is equally spread. Hence data appears liner with no heteroscedasticity.

Now, the mediation process was run to measure the direct and indirect affect.

Table 4.3: Mediated Regression Analysis

\begin{tabular}{lccccc}
\hline Predictors & Coefficient & $\mathbf{T}$ & $\mathbf{P}$ & LLCI & ULCI \\
\hline EI JI & .7410 & 3.4527 & .000 & & \\
EI PQC & .3447 & 5.1856 & .000 & & \\
JI PQC & .5040 & 8.4981 & .000 & & \\
Direct Effect & .3447 & 5.1856 & .000 & .2137 & .4756 \\
Indirect Effect & .3735 & & & .2725 & .4807 \\
\hline
\end{tabular}

Regression examination was applied to examine the theory that job involvement mediates the association of emotional intelligence and patient's quality of care. The results specified that emotional intelligence was an important predictor of job involvement, $\mathrm{B}=0.74, \mathrm{SE}=0.055, \mathrm{p}<0.05$, and job involvement was a significant predictor of quality of care, $B=0.504, \mathrm{SE}=0.0593 \mathrm{p}<0.05$. These outcomes supported researcher meditational hypothesis. The impact of emotional intelligence on patient's quality of care was still significant in the presence of job involvement as mediator, $\mathrm{B}=0.345, \mathrm{SE}=0.067 \mathrm{p}<0.05$. Hence, there was a partial mediation present in the proposed model. Approximately $55 \%$ of the variance in patient's quality of care was accounted by the predictors with $R^{2}=0.546$. 


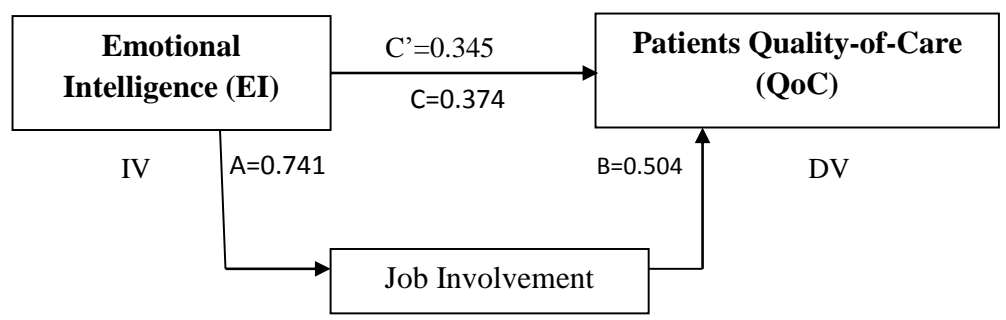

The direct effect of emotional intelligence on patient's quality of care $B=0.34, \mathrm{SE}=0.06 \mathrm{p}<0.05$. The passive effect was tested using bootstrap samples for percentile method with 5000 samples through Process macro version-3 (Hayes et al., 2017). The results depicted that indirect coefficient was significant, $\mathrm{B}=0.374, \mathrm{SE}=0.052,95 \% \mathrm{CI}=0.27,0.48$. Hence the Emotional Intelligence was related with approximately 0.37 facts higher quality of care scores as facilitated by job involvement. It is observed by the results that job involvement as mediating variable has positive relationship between emotional intelligence and patient quality of care.

\section{Discussion}

The purpose of this research work was to bring light to the influence of nurse's emotional intelligence on patient's quality-of-care and via job involvement. There was number of studies that examined the role emotional intelligence in nursing profession however, there is a lack of evidence for research in Pakistan prospective. With the understanding of nurse's emotions through emotional intelligence various questions relating to patient's quality of care might be answered.

The statistical outcomes confirmed nurses' emotional intelligence positively affects patient's quality of care. Furthermore, the association between emotional intelligence and job involvement and patient's quality of care are also positive. Job involvement has a partial mediation impact in the said association. As for this current research study different research methods used for checking the validity and reliability of variables. For checking the reliability Cronbach's Alpha was used the result was significant. For observing the relationship among variables Pearson correlation method used and it shows that there is strong correlation relationship between all variables. For examining the mediation analysis among variables mediation analysis through regression used which shows that due to the involvement of mediating variable there is strong association between emotional intelligence and job involvement and also strong association between job involvement and patient quality of care where as the association between emotional intelligence and patient quality of care partial.

\subsection{Future Recommendations}

The future research work should be conducted in longitudinal study with large sample size of nurse. Also, a comparative research study will be organized to observe the nurse's emotional intelligence of public and private hospitals. In the current study the demographic factors did not reflect. The future researcher should use demographic factors as a predictor variable in healthcare sector. 


\section{References}

Ahangar, R. G. (2012). Emotional intelligence: The most potent factor of job performance among executives. Emotional Intelligence-New Perspectives and Applications, 1(1):121-138.

Berghout, M., van Exel, J., Leensvaart, L., and Cramm, J. M. (2015). Healthcare professionals views on patient-centered care in hospitals. BMC health services research, 15(1):385.

Bertakis, K. D., Azari, R., Helms, L. J., Callahan, E. J., and Robbins, J. A. (2000). Gender differences in the utilization of health care services. Journal of family practice, 49(2):147-147.

Birks, Y. F. and Watt, I. S. (2007). Emotional intelligence and patient-centred care. Journal of the Royal society of medicine, 100(8):368-374.

Biswas, S. (2009). Job satisfaction and job involvement as mediators of the relationship between psychological climate and turnover intention. South Asian Journal of Management, 16(1):27.

Bryman, A. and Becker, S. (2012). Qualitative research.

Celik, G. O. (2017). The relationship between patient satisfaction and emotional intelligence skills of nurses working in surgical clinics. $P a-$ tient preference and adherence, 11:1363.

Cooper, A. and Petrides, K. V. (2010). A psychometric analysis of the trait emotional intelligence questionnaire-short form (teique-sf) using item response theory. Journal of personality assessment, 92(5):449-457.

Ćulibrk, J., Delić, M., Mitrović, S., and Ćulibrk, D. (2018). Job satisfaction, organizational commitment and job involvement: the mediating role of job involvement. Frontiers in psychology, 9:132.

Dandona, R., Dandona, L., Srinivas, M., Giridhar, P., Nutheti, R., and Rao, G. N. (2002). Planning low vision services in india: a population-based perspective. Ophthalmology, 109(10):1871-1878.

DeCarufel, A. and Schaan, J.-L. (1990). The impact of compressed work weeks on police job involvement. Canadian Police College Journal.
Delaney, L. J. (2018). Patient-centred care as an approach to improving health care in australia. Collegian, 25(1):119-123.

Ezzatabadi, M. R., Bahrami, M. A., Hadizadeh, F., Arab, M., Nasiri, S., Amiresmaili, M., and Tehrani, G. A. (2012). Nurses' emotional intelligence impact on the quality of hospital services. Iranian Red Crescent Medical Journal, 14(12):758.

Ferrara, J., Diamond, A., Hunter, C., Davidson, A., Almaguer, M., and Jankovic, J. (2010). Impact of stn-dbs on life and health satisfaction in patients with parkinson's disease. Journal of Neurology, Neurosurgery \& Psychiatry, 81(3):315-319.

Griffin, M. L., Hogan, N. L., and Lambert, E. G. (2012). Doing people work in the prison setting: An examination of the job characteristics model and correctional staff burnout. Criminal Justice and Behavior, 39(9):1131-1147.

Gülay Ogelman, H., Oğuz, V., Körükçü, Ö., and Köksal Akyol, A. (2017). Examination of the effect of perspective-taking skills of six-year-old children on their social competences. Early Child Development and Care, 187(1):59-67.

Hayes, A. F., Montoya, A. K., and Rockwood, N. J. (2017). The analysis of mechanisms and their contingencies: Process versus structural equation modeling. Australasian Marketing Journal (AMJ), 25(1):76-81.

Hayes, A. F. and Preacher, K. J. (2010). Quantifying and testing indirect effects in simple mediation models when the constituent paths are nonlinear. Multivariate behavioral research, 45(4):627660.

Hudson, P. L., Aranda, S., and Kristjanson, L. J. (2004). Meeting the supportive needs of family caregivers in palliative care: challenges for health professionals. Journal of palliative medicine, 7(1):19-25.

Ismail, F. Y., Fatemi, A., and Johnston, M. V. (2017). Cerebral plasticity: windows of opportunity in the developing brain. European Journal of Paediatric Neurology, 21(1):23-48.

Jans, N. (1985). Organizational factors and work involvement. Organizational behavior and human decision processes, 35(3):382-396. 
Jayadevappa, R. (2017). Patient-centered outcomes research and patient-centered care for older adults: A perspective. Gerontology and geriatric medicine, 3:2333721417700759.

Kalhor, R., Khosravizadeh, O., Moosavi, S., Heidari, M., and Habibi, H. (2018). Role of organizational climate in job involvement: A way to develop the organizational commitment of nursing staff. Journal of evidence-based integrative medicine, 23:2515690X18790726.

Kappagoda, U., Othman, P., Zainul, H., and Alwis, G. (2014). Psychological capital and job performance: The mediating role of work attitudes. Dr. Hohd. Zainul and Alwis, Gamini, Psychological Capital and Job Performance: The Mediating Role of Work Attitudes (June 27, 2014). Journal of Human Resource and Sustainability Studies.

Khan, A., Masrek, M. N., and Nadzar, F. M. (2017). Emotional intelligence and job satisfaction of academic librarians: An assessment of the relationship. Journal of Librarianship and Information Science, 49(2):199-210.

Kooker, B. M., Shoultz, J., and Codier, E. E. (2007). Identifying emotional intelligence in professional nursing practice. Journal of Professional Nursing, 23(1):30-36.

Kreindler, S. A., Larson, B. K., Wu, F. M., Carluzzo, K. L., Gbemudu, J. N., Struthers, A., Van Citters, A. D., Shortell, S. M., Nelson, E. C., and Fisher, E. S. (2012). Interpretations of integration in early accountable care organizations. The Milbank Quarterly, 90(3):457-483.

Lin, Y.-C. (2013). The effects of job involvement on emergency medical technicians in taiwans fire organization. Safety science, 59:227-236.

Mahmoud, H. G. (2017). Job crafting and work involvement as a mediator to promote head nurses' organizational citizenship behavior at mansoura university hospitals. International journal of Nursing Didactics, 7(12):01-09.

Metcalfe, T. (2017). Perception of speech, music and emotion by hearing-impaired listeners. PhD thesis, University of Sheffield.
Miao, C., Humphrey, R. H., and Qian, S. (2016). Leader emotional intelligence and subordinate job satisfaction: A meta-analysis of main, mediator, and moderator effects. Personality and Individual Differences, 102:13-24.

Mwachofi, A., Walston, S. L., and Al-Omar, B. A. (2011). Factors affecting nurses' perceptions of patient safety. International journal of health care quality assurance.

Nightingale, S., Spiby, H., Sheen, K., and Slade, P. (2018). The impact of emotional intelligence in health care professionals on caring behaviour towards patients in clinical and long-term care settings: Findings from an integrative review. International journal of nursing studies, 80:106-117.

Obaidi, M., Kunst, J. R., Kteily, N., Thomsen, L., and Sidanius, J. (2018). Living under threat: Mutual threat perception drives anti-muslim and anti-western hostility in the age of terrorism. European Journal of Social Psychology, 48(5):567-584.

Paterson, J. M. and O'Driscoll, M. P. (1990). An empirical assessment of kanungo's (1982) concept and measure of job involvement. Applied Psychology, 39(3):293-306.

Preacher, K. J. and Hayes, A. F. (2008). Asymptotic and resampling strategies for assessing and comparing indirect effects in multiple mediator models. Behavior research methods, 40(3):879-891.

Raghubir, A. E. (2018). Emotional intelligence in professional nursing practice: A concept review using rodgers's evolutionary analysis approach. International journal of nursing sciences, 5(2):126130.

Salomon, L., Gasquet, I., Mesbah, M., and Ravaud, P. (1999). Construction of a scale measuring inpatients' opinion on quality of care. International journal for quality in health care, 11(6):507-516.

Shahnavazi, M., Parsa-Yekta, Z., Yekaninejad, M.S., Amaniyan, S., Griffiths, P., and Vaismoradi, M. (2018). The effect of the emotional intelligence education programme on quality of life in haemodialysis patients. Applied Nursing Research, 39:18-25.

Singh, M. and Sarkar, A. (2012). The relationship between psychological empowerment and innovative behavior. Journal of Personnel Psychology. 
Sreejesh, S., Mohapatra, S., and Anusree, M. (2014). Business research methods: An applied orientation. Springer.

Ting, S.-C. (2014). Organizational justice influences foci commitment of teachers via trust. International Journal of Learning, Teaching and Educational Research, 7(1).

Wang, J., Guerra, R., and Cohen, J. (1999). A statistically robust variance-components approach for quantitative trait linkage analysis. Annals of human genetics, 63(3):249-262.

Yao, X., Yuan, S., Yang, W., Chen, Q., Wei, D., Hou, Y., Zhang, L., Qiu, J., and Yang, D. (2018). Emotional intelligence moderates the relationship between regional gray matter volume in the bilateral temporal pole and critical thinking disposition. Brain imaging and behavior, 12(2):488498. 